\title{
Clinical and Social Variables Association on the Frequency of Intellectual Disability Persons to Dental Care
}

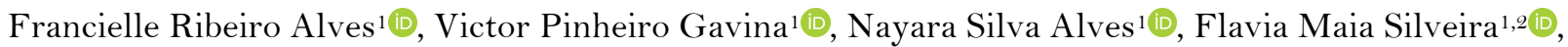

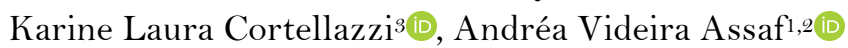

${ }^{1}$ Postgraduate Program in Dentistry, Fluminense Federal University, Nova Friburgo, RJ, Brazil.

${ }^{2}$ Department of Specific Formation, School of Dentistry, Fluminense Federal University, Nova Friburgo, RJ, Brazil.

${ }^{3}$ Department of Public Health, School of Dentistry, Unicamp, Piracicaba, SP, Brazil.

Correspondence: Francielle Ribeiro Alves, Rua Professor Lara Vilela, 201, 402 Ingá, Niterói, RJ, Brazil. E-mail: francielleribeiroalves@gmail.com

Academic Editor: Alessandro Leite Cavalcanti

Received: 18 April 2020 / Review: 24 July 2020 / Accepted: 11 August 2020

How to cite: Alves FR, Gavina VP, Alves NS, Silveira FM, Cortellazzi KL, Assaf AV. Clinical and social variables association on the frequency of intellectual disability persons to dental care. Pesqui Bras Odontopediatria Clín Integr. 2021 ; 21:e0073. https://doi.org/10.1590/pboci.2021.093

\begin{abstract}
Objective: To evaluate the association of oral health indicators and social variables on the frequency of visit to the dentist by persons with intellectual disability (ID). Material and Methods: The study comprised a sample consisting of 149 participants with ID, aged from 11 to 29 years, from non-governmental institutions. Semi-structured interviews were held to collect sociodemographic and psychosocial information with their parents/guardians, followed by oral health evaluations in accordance with World Health Organization criteria. Crude analyses and multiple analysis were conducted to test whether oral health indicators and social data were predictors of the visit to dental care services. Results: In the multiple logistic regression model, individuals with lower DMF-t $(\mathrm{OR}=3.13 ; 95 \% \mathrm{CI}=1.40-6.97)$ and those with less crowded housing $(\mathrm{OR}=2.33 ; 95 \% \mathrm{CI}=1.06-5.12)$ presented less frequency of visits to oral health services. Conclusion: DMFT and crowded housing are associated to the frequency of persons with intellectual disability to dental care as well as this outcome measure affects the oral health of persons with ID. Therefore, identifying limiting factors to dental care of persons with intellectual disability is needed so that this group can receive adequate attention.
\end{abstract}

Keywords: Health Services; Intellectual Disability; Persons with Mental Disabilities; Oral Health. 


\section{Introduction}

According to the American Association on Intellectual and Developmental Disabilities (AAIDD), persons with Intellectual Disability (ID) present substantial limitation of learning capacity and skills required in their everyday lives, associated with adaptive limitations in at least two skills (self-care, homelife, social, health and work adaptation) [1]. Analogously, the Diagnostic and Statistical Manual of Mental Disorders, 5th edition (DSM-5) defined intellectual disability are classified according to adaptive functioning, represented by memory, knowledge, language, social interaction and self-care [2].

The World Health Organization (WHO) has estimated that $15.6 \%$ of the world adult population has some type of disability, including persons with ID [3]. According to the 2010 Census, considering Brazil's population, $23.9 \%$ of people have at least one of the disabilities being investigated: visual, auditory, motor, and mental or intellectual, and of these people, $1.40 \%$ (2.617.025) present mental or intellectual disability [4].

The WHO Convention about the Rights of Persons with Disabilities also recommends disabled persons the right to use goods and services in health, without them being subjected to any type of discrimination $[5,6]$.

However, there are barriers to the use of health services, especially for disabled persons, that may include the appropriate training of health professionals, the suitability of technological resources, and even the desire or need of caregivers to take disabled persons for care, thereby making difficult to provide them with opportunities equal to those of the entire population. Also, the possibility of obtaining care according to needs is interrelated to the resoluteness and may be under the influence of social determinants of health [5-7].

Nevertheless, a large portion of this population is unassisted as regards oral health care [8]. This is mainly attributed to the barriers to health care that still exist, such as, for example, lack of accessibility to oral health services, insufficiency of appropriate and resolutive services for persons with ID, which meet their demands. This increases the risks of compromising their oral health and quality of life even further [9-11]. Through this context, this study aimed to evaluate the association of oral health indicators and sociodemographic and psychosocial variables on the frequency of persons with intellectual disability to oral health care services.

\section{Material and Methods}

Ethical Aspects

The project was approved by the Research Ethics Committee (CEP CMM/HUAP nº 061/09).

\section{Study Design}

An observational, cross-sectional study was developed, with an analytical component and in accordance with the recommendations of STROBE [12].

\section{Sample and Recruiting}

The study was conducted from a population of adolescents and young adults, from 11-29 years of age, with complete permanent dentition [13,14] and with intellectual disability (ID), from four psychosocial care institutions for persons with disabilities in the municipality of Nova Friburgo, RJ, Brazil, in the year of 2016. From those institutions, only one public institution offered dental care, especially directed to assistance and urgencies. Based on a previous study [15], there are a total of approximately 200 persons with ID who frequented the institutions. The option was taken to evaluate all the individuals who agreed to participate in 
the study. However, it is important to emphasize that the sample size of 149 participants provided the test power of $80 \%(\beta=0.20)$ with a significance level of $5 \%(\alpha=0.05)$ for the effect size found in the study (Odds Ratio of 3.0 and $40 \%$ response in the unexposed group - DMFT variable).

The inclusion criteria comprised the voluntary participation and consent of the guardians and their respective participants with ID, or ID associated with other conditions, such as Attention Deficit and Behavioural Disturbance, of both sexes.

\section{Data Collection}

Data collection was conducted in three stages: i) Pilot study, examiner training and calibration; ii) Application of questionnaires; iii) Clinical exam.

\section{Pilot study, Examiner Training and Calibration}

Before beginning with the field stage, a pilot study was conducted with 10 individuals with ID and their guardians to verify the understanding of the questions by the guardians; to train the researchers in conducting the interviews by using a language suited to the studied population. The calibration process for the clinical exam for dental caries and need for dental prosthesis consisted of theoretical-clinical training of a single examiner for 24 hours. Initially, a theoretical discussion lasting 4 hours was performed. A standard examiner (A.V.A.) gave a precise theoretical explanation on the indexes' codes and criteria, and after that, a theoretical-expository exercise was carried out, from the photos exhibition of each clinical situation possible to be found in the exams. After that, a practical training phase was followed in three four hour period, and discussions between the examiner and the standard examiner were allowed, in relation to clinical findings, diagnostic criteria, coding and registration errors, with the purpose of reaching an acceptable level of agreement. In two 4-hour periods, the examiner's calibration was performed. In this phase, a group of 10 individuals with ID was assessed twice, with an interval of one week between each assessment to obtain intraexaminer agreement for all clinical examined conditions using the Kappa statistic.

\section{Application of the Questionnaires: Quantitative Measurement Instrument}

Interviews were held in a private internal room of each institution with a trained interviewer using a semi-structured questionnaire held with the ID participants' guardians. It is important to point out that those guardians were only the subjects responsible for providing information of a social nature, with individuals with ID being the study participants. The questionnaires were applied to collect information relative to the following: socioeconomic and demographic characterization of the family and frequency of ID participants to dental services [16] and psychosocial characterization, measured by using the Medical Outcomes Study's social support scale (Portuguese version), considering network and social support from three dimensions: positive social interaction/affective support, emotional/information support and material support [17].

\section{Clinical Evaluation}

According to the WHO criteria [18], clinical evaluation was performed to observe the following oral health diseases: dental caries and need for dental prosthesis. Epidemiological examinations were performed by a calibrated examiner in an indoor setting, using common chairs, under the visual-tactile method, with resources of examination such as artificial light, flat mouth mirror, periodontal probe (WHO 621), and previous dental brushing. The values obtained were recorded by a take note on examination cards. 


\section{Statistical Analysis}

Initially, descriptive analyses were made. The relative frequency was obtained for characterizing the sample, clinical exam and the component items of the questionnaire for non-clinical characterization. After this, the association between the oral health indicators, socio demographic and psychosocial variables (social support and network) were tested relative to the measurement of frequency of ID participants to dental care services. Dental caries was measured by DMFT index (decayed, missing and filled teeth) and need for prosthesis was evaluated by the number of individuals needing a prosthesis, in the superior or inferior dental arch. It is important to report that the social support measure was calculated from the total sum of the scores related to the three dimensions described above: positive social interaction/affective support, emotional/information support, which was later dichotomized by the median [17].

\section{Studied Variables}

The variables were dichotomized and the median was used to establish a cutoff and obtain standardization and homogeneity of the distribution of variables. As a dependent variable, the interval of the last visit to the dentist $(\leq 1$ year; $>1$ year) was considered. The independent variables were categorized as follows: age ( 11 to 19 , and 20 to 29 years); sex (female and male); DMF-t (decayed, missing and filled teeth index, dichotomized by the median at 6 points: $\leq 6$; $>6$ ); family income (dichotomized by the median at 3 points: $\leq 3$ Brazilian minimum wages (BMW); $>3$ BMW); educational years (dichotomized by the median at 5 points: $\leq 5$ years of schooling; $>5$ years of schooling); treatment needs (yes; no), need for dentures (yes; no), toothache in the last 6 months (yes; no), presence of caries (yes; no), reason for consultation (review, pain, treatment), type of service (public, private), social support (dichotomized by the median at 7 points: $\leq 7 ;>7$ ) and network (dichotomized by the median at 65 points: $\leq 65 ;>65$ ); and housing crowding (dichotomized by the median at 2 points: $\leq 2 ;>2$ ). The variable housing crowding must be calculated by dividing the number of participants who live in the house by the number of bedrooms [19,20]. It is important to point out that the treatment needs variable was assessed by guardians report [16] and not by clinical evaluation of ID participants.

The Chi-square or Exact Fisher test was used to test the association of the independent variables with the dependent variable. The variables that presented $p<0.20$ in the crude analysis were tested in the multiple logistic regression model with the forward stepwise procedure. The Odds Ratio $(\mathrm{OR})$ and respective confidence intervals of $95 \%$ (CI) were estimated for the variables that remained in the final model, at the level of significance of $5 \%$. The statistical tests were performed in the software SAS, version 9.4 (SAS Institute Inc., North Carolina, USA).

For the mean intraexaminer agreement on the clinical evaluations, in the calibration and field periods, the Kappa coefficient of agreement was used for all clinical examined conditions (dental caries and need for prothesis.

\section{Results}

The intraexaminer Kappa Coefficient values during the calibration and field stages were above 0.90 for all oral diseases. With regard to the questionnaire that was used to measure psychosocial factors (social support and network) [17], the internal consistency was shown to be high for all the domains (Cronbach Alpha $=0.96$ ) and instrument stability, measured by the Intraclass Correlation Coefficient - ICC - was shown to be satisfactory only for the positive social interaction domain $(\mathrm{ICC}=0.71)$. 
The final sample was composed of 149 participants with ID, considering that 182 were invited to participate, thus attaining a response rate of $84.6 \%$.

Table 1 presents the sample distribution according to the oral health indicators and socio demographic characteristics. Presence of dental caries was found in 63 (42.28\%) individuals and 86 (57.71\%) were caries-free. The mean DMF-t index was 7.41 (standard deviation=6.03), with 56 (37.58\%) individuals reporting toothache and 47 (31.54\%) showed a need for dental prosthesis.

Table 1. Distribution of participants with ID.

\begin{tabular}{|c|c|c|c|}
\hline Variables & Category & $\mathbf{N}$ & $\%$ \\
\hline \multirow[t]{2}{*}{ Age (Years) } & 11 to 19 & 97 & 65.11 \\
\hline & 20 to 29 & 52 & 34.89 \\
\hline \multirow[t]{2}{*}{ Gender } & Female & 58 & 38.92 \\
\hline & Male & 91 & 61.08 \\
\hline \multirow[t]{2}{*}{ Income $(\mathrm{BMW})^{*}$} & $\leq 3$ & 127 & 92.03 \\
\hline & $>3$ & 11 & 7.97 \\
\hline \multirow[t]{2}{*}{ Treatment Need } & Yes & 127 & 85.81 \\
\hline & No & 21 & 14.19 \\
\hline \multirow[t]{2}{*}{ Toothache } & Yes & 56 & 38.36 \\
\hline & No & 90 & 61.64 \\
\hline \multirow[t]{2}{*}{ Visit To Dentist } & Yes & 142 & 95.31 \\
\hline & No & 7 & 4.69 \\
\hline \multirow[t]{2}{*}{ Last Consultation } & $\leq 1$ Year & 101 & 67.78 \\
\hline & $>1$ Year & 48 & 32.22 \\
\hline \multirow[t]{2}{*}{ Presence of Caries } & No & 86 & 57.72 \\
\hline & Yes & 63 & 42.28 \\
\hline \multirow[t]{3}{*}{ Reason for Consultation } & Review & 64 & 45.71 \\
\hline & Pain & 21 & 15.00 \\
\hline & Treatment & 55 & 39.29 \\
\hline \multirow[t]{2}{*}{ Type of Service } & Public & 99 & 69.23 \\
\hline & Private & 44 & 30.77 \\
\hline \multirow[t]{2}{*}{ Need for Dentures } & Yes & 47 & 31.55 \\
\hline & No & 102 & 68.45 \\
\hline \multirow[t]{2}{*}{ Years of Education } & $\leq 5$ & 86 & 61.43 \\
\hline & $>5$ & 54 & 38.57 \\
\hline \multirow[t]{2}{*}{ DMFT } & $\leq 6$ & 78 & 52.35 \\
\hline & $>6$ & 71 & 47.65 \\
\hline \multirow[t]{2}{*}{ Network } & $\leq 7$ & 82 & 55.04 \\
\hline & $>7$ & 67 & 44.96 \\
\hline \multirow[t]{2}{*}{ Social Support } & $\leq 65$ & 77 & 53.10 \\
\hline & $>65$ & 68 & 46.90 \\
\hline \multirow[t]{2}{*}{ Agglomeration } & $\leq 2$ & 110 & 73.83 \\
\hline & $>2$ & 39 & 26.17 \\
\hline
\end{tabular}

*Brazilian Minimum Wage (BMW) in 2016.

The results in Table 2 show that the use of public services is the most frequent, regardless of age group. The variables DMFT, need for prosthesis show a proportional increase with age, as well as a decrease in caries-free individuals with time. The number of individuals who have already been to the dentist increases, as does the decrease in the interval of the last appointment over the years. There is a decrease in the number of individuals with a history of dental pain, as well as treatment needs. At the same time, it appears that consultations for review increase in the group of young adults.

Table 3 presents the crude and adjusted analysis of the interval of the last visit to the dentist and associated factors. In the crude analysis, the longest interval of the last visit to the dentist was associated with the lower DMF-t $(\mathrm{OR}=2.09 ; 95 \% \mathrm{CI}=1.03-4.26)$ and reason for visit to the dentist for pain and treatment when 
compared to dental revision $(\mathrm{OR}=2.06 ; 95 \% \mathrm{CI}=1.00-4.28)$. In the multiple analysis, the independent variables, lower DMF-t $(\mathrm{OR}=3.13 ; 95 \% \mathrm{CI}=1.40-6.97)$ and less crowded housing $(\mathrm{OR}=2.33 ; 95 \% \mathrm{CI}=1.06-5.12)$ were associated with the longest interval of the last consultation. Some psychosocial and socioeconomic variables showed no statistical relevance when associated with the frequency of ID participants to dental services.

Table 2. Distribution of individuals with ID, according to age group.

\begin{tabular}{llcc}
\hline \multicolumn{1}{c}{ Variables } & \multicolumn{1}{c}{ Categories } & 11-19 Years Old & 20-29 Years Old \\
& & N $(\%)$ & N (\%) \\
\hline Treatment Need & Yes & $88(90.72)$ & $39(76.47)$ \\
Toothache & No & $9(9.28)$ & $12(23.53)$ \\
& Yes & $40(42.11)$ & $16(31.37)$ \\
Visit to Dentist & No & $55(57.89)$ & $35(68.63)$ \\
& Yes & $90(92.78)$ & $52(100.00)$ \\
Last Consultation & No & $7(7.22)$ & $0(0.00)$ \\
& $\leq 1$ Year & $57(63.33)$ & $37(71.15)$ \\
Presence of Caries & $>1$ Year & $33(36.67)$ & $15(28.85)$ \\
& No & $15(15.79)$ & $5(9.62)$ \\
Reason for Consultation & Yes & $80(84.21)$ & $47(90.38)$ \\
& Review & $40(42.55)$ & $26(52.00)$ \\
Type of Service & Pain & $15(15.96)$ & $7(14.00)$ \\
& Treatment & $39(41.49)$ & $17(34.00)$ \\
Need for Dentures & Public & $70(72.92)$ & $31(59.62)$ \\
& Private & $26(27.08)$ & $21(40.38)$ \\
DMFT & Yes & $23(22.55)$ & $25(48.08)$ \\
\hline
\end{tabular}

Table 3. Oral health and social variables associated with an interval of last oral health consultation of participants with intellectual disability.

\begin{tabular}{|c|c|c|c|c|c|c|c|c|c|c|}
\hline \multirow{3}{*}{ Variables } & \multicolumn{4}{|c|}{ Interval of Last Consultation } & \multicolumn{3}{|c|}{ Crude Analysis } & \multicolumn{3}{|c|}{ Adjusted Analysis } \\
\hline & \multicolumn{2}{|c|}{$\leq 1$ Year } & \multicolumn{2}{|c|}{$>1$ Year } & \multirow[t]{2}{*}{ OR } & \multirow[t]{2}{*}{ CI $95 \%$} & \multirow[t]{2}{*}{ p-value } & \multirow[t]{2}{*}{ OR } & \multirow[t]{2}{*}{ CI $95 \%$} & \multirow[t]{2}{*}{ p-value } \\
\hline & $\mathrm{N}$ & $\%$ & $\mathrm{~N}$ & $\%$ & & & & & & \\
\hline \multicolumn{11}{|l|}{ Age (Years) } \\
\hline 11 to 19 & 64 & 65.98 & 33 & 34.02 & 1.27 & $0.61-2.64$ & 0.5198 & & & \\
\hline 20 to 29 & 37 & 71.15 & 15 & 28.85 & Ref & & & & & \\
\hline \multicolumn{11}{|l|}{ Sex } \\
\hline Female & 40 & 68.97 & 18 & 31.03 & Ref & & & & & \\
\hline Male & 61 & 67.03 & 30 & 32.97 & 1.09 & $0.54-2.22$ & 0.8056 & & & \\
\hline \multicolumn{11}{|l|}{ DMF-T } \\
\hline$\leq 6$ & 47 & 60.26 & 31 & 39.74 & 2.09 & $1.03-4.26$ & 0.0409 & 3.13 & $1.40-6.97$ & 0.0053 \\
\hline$>6$ & 54 & 76.06 & 17 & 23.94 & Ref & & & Ref & & \\
\hline \multicolumn{11}{|l|}{ Family Income* } \\
\hline$\leq 3 \mathrm{BMW}$ & 85 & 66.93 & 42 & 33.07 & 2.22 & $0.46-10.75$ & 0.3204 & & & \\
\hline$>3 \mathrm{BMW}$ & O9 & 81.82 & 2 & 18.18 & Ref & & & & & \\
\hline \multicolumn{11}{|l|}{ Education $\#$} \\
\hline$\leq 5$ Years & 56 & 65.12 & 30 & 34.88 & 1.27 & $0.61-2.65$ & 0.5198 & & & \\
\hline$>5$ Years & 38 & 70.37 & 16 & 29.63 & Ref & & & & & \\
\hline \multicolumn{11}{|l|}{ Treatment Need } \\
\hline No & 18 & 85.71 & 3 & 14.29 & Ref & & & Ref & & \\
\hline Yes & 82 & 64.57 & 45 & 35.43 & 3.29 & $0.92-11.78$ & 0.0670 & 3.41 & $0.87-13.37$ & 0.0784 \\
\hline \multicolumn{11}{|c|}{ Need for Dentures } \\
\hline No & 71 & 69.61 & 31 & 30.39 & Ref & & & & & \\
\hline Yes & 30 & 63.83 & 17 & 36.17 & 1.30 & $0.63-2.69$ & 0.4836 & & & \\
\hline \multicolumn{11}{|l|}{ Toothache } \\
\hline No & 65 & 72.22 & 25 & 27.78 & Ref & & & & & \\
\hline Yes & 35 & 62.50 & 21 & 37.50 & 1.56 & $0.77-3.18$ & 0.2202 & & & \\
\hline
\end{tabular}




\begin{tabular}{|c|c|c|c|c|c|c|c|c|c|c|}
\hline \multicolumn{11}{|l|}{ Reason for Visit } \\
\hline Review & 48 & 75.00 & 16 & 25.00 & Ref & \multicolumn{5}{|c|}{ Ref } \\
\hline Pain/Treatment & 45 & 59.21 & 31 & 40.79 & 2.06 & $1.00-4.28$ & 0.0506 & 2.06 & $0.93-4.57$ & 0.0752 \\
\hline \multicolumn{11}{|l|}{ Type of Service } \\
\hline Public & 68 & 68.69 & 31 & 31.31 & Ref & & & & & \\
\hline Private & 27 & 61.36 & 17 & 38.64 & 1.38 & $0.66-2.90$ & 0.3929 & & & \\
\hline \multicolumn{11}{|l|}{ Network } \\
\hline$\leq 7$ & 52 & 63.41 & 30 & 36.59 & 1.57 & $0.78-3.17$ & 0.2080 & & & \\
\hline$>7$ & 49 & 73.13 & 18 & 26.87 & Ref & & & & & \\
\hline \multicolumn{11}{|l|}{ Social Support } \\
\hline$\leq 65$ & 50 & 64.94 & 27 & 35.06 & 1.39 & $0.69-2.82$ & 0.3585 & & & \\
\hline$>65$ & 49 & 73.42 & 19 & 27.94 & Ref & & & & & \\
\hline \multicolumn{11}{|l|}{ Agglomeration } \\
\hline$\leq 2$ & 43 & 61.43 & 27 & 38.57 & 1.73 & $0.87-3.47$ & 0.1197 & 2.33 & $1.06-5.12$ & 0.0347 \\
\hline$>2$ & 58 & 73.42 & 21 & 26.58 & Ref & & & Ref & & \\
\hline
\end{tabular}

Ref: Reference; *Brazilian Minimum Wage (BMW) in 2016; \#Years of Schooling.

\section{Discussion}

The study addresses a population, mostly with low income and a few years of study in parallel to an epidemiological scenario of a high prevalence of dental caries, relevant need for dentures and other dental treatment needs. Almost all participants (95.30\%) had been to the dentist sometimes in their lives, and the majority $(67.78 \%)$ had been to the dentist within a year or less. Such a result is in accordance with other studies that have shown considerable use of oral health services by disabled persons $[17,18]$. This improvement can be considered positive for the oral health of this group; however, this cannot guarantee resolution or reduction of demands or even the integrality of oral health attention. Therefore, the question that still should be asked is: what are the obstacles to the use of dental care services by persons with ID? The question arises because the number of these persons seeking oral health attendance has still been considered lower for this type of population and generally, not all demands are resolved when compared with persons without disabilities [11,21-24].

Economic questions are almost always emphasized in studies related to the use of health services $[9,10]$, with an inverse relationship between the social situation of individuals and the possibility of use being constant in these references. This study showed no significant ratio for some of the social variables such as income and education; however, crowded housing presented a relevant variable of frequency of oral health care use by the individuals. Contrary to expectations [19,20], the result showed that persons with ID who resided in homes with less crowded housing - that is, better socioeconomic conditions, presented less access to health services. This may be justified because this group - theoretically more economically favoured - tended to present fewer oral health problems, and thus, they also sought fewer dental care services. To begin with, as they had better living conditions, they would present lower assistance needs. Corroborating this affirmative, in this sample, a positive correlation was observed regarding the variables DMF-t and crowded housing $(p=0.03)$, which indicated that individuals with higher DMF-t indexes belonged to the group with a higher level of crowded housing. However, it is also relevant to observe that the visit to a dentist may be related not only to an ID person's need to perform dental treatment but also to the guardian's desire to take him/her to visit a dentist.

Furthermore, a greater frequency of dental care services was also related to the group with the highest DMF-t index, and this finding was probably due to the demand for attendance by individuals who already had a high burden of oral disease. Besides, the fact that healthier individuals (with lower DMFT) living in more spacious accommodations (less crowded) have less access to care also may be due to the caregivers 
frequently consider as priority other general health care demands than those related to oral health. This may be corroborated by studies that did not indicate difficulties of using oral health services by persons with ID, although those also have pointed out that, in these cases, easy access was more frequently related to care sought in cases of urgency [25].

As regard the nature of the service provided, public attendance was sought by over half of the disabled users $(69.23 \%)$, especially from the younger subgroup (72.92\%). These results suggested that there had been the use of ID persons to dental services, although there was still a large portion of them with persistent treatment needs. It could indicate that the oral health attention model in this municipality still shows deficiencies for oral health promotion of disabled persons.

It should be pointed out that primary care must function, as a priority, as a point of entry into the other levels of care, seeking a greater degree of resolution of actions from a health promotion perspective. However, if dental needs continue to be high in spite of this, as observed in the studied group, the authors suppose that there are difficulties to the use of dental services at this level of attention $[7,10,26]$. This fact may suggest the presence of social factors and problems in the services' organization that limit integral health care. Also, these reflect directly on the epidemiological response of high levels of oral diseases in this population or even a possible low number of professionals trained for performing the attendance of disabled patients [11].

It is of the utmost importance to mention that the frequency of service's use will also depend on the users' and caregivers' perception of the need [9] or even the desire to visit a dentist [27]. In other words, this may indicate that dental treatments sometimes are not related to dental care priorities, but there may have the influence of external and complex factors that influence the caregivers' perception, as opposed to the patients' real needs. A more coherent perception of objective oral conditions would probably motivate persons to take more care of their own oral health [27].

The assistance provided is generally related to the way health services are organized and the reason for an individual's search and demand for dental care [6,7]. In this study, the data obtained showed that most dentists performed review consultations, characterizing one of the main reasons for seeking dental consultations (45.71\%), especially for the older subgroup (52\%). A previous study pointed out that in some places, in addition to the delay in obtaining an appointment for highly complex cases, there is a lack of reference service in dentistry [28].

It should be noted here that the persistence of treatment needs, despite the possibility of using a dental service, also suggested that this population has not received continued dental care, which favors an increase in treatment demands and in the non-resolution of cases of this population. Therefore, there is a need for these individuals to have access to an integral and continuous care model based on health promotion and dental assistance while contributing to the reduction of dental needs.

The analysis of the frequency of dental service use for ID persons was the objective of this study, similar to others about this theme [27-29]. The focus on the caregiver is a relevant item, since in most cases, individuals with ID are not fully independent, and parents/ caregivers are mainly responsible for their health.

We also suggest that families' low priority to early dental care may be caused by challenges on the part of the guardians because of possible health conditions of these patients who are demanding continuous care for the maintenance of life, do not have easy access to oral health care, leading thus to a high number of adults giving priority to treatment under sedation and/or to general anesthesia [30-32].

The present study had some limitations because it concerned a universe obtained from census data that had a relatively homogeneous behavior. This may explain the fact that some variables such as income and 
years of education presented no significant relationship with the frequency of ID persons to dental care, and because the subjects were institutionalized individuals. The classification according to the degree of intellectual disability was not possible to be recorded in the study, due to the absence of this information in the medical records, in most cases, even though the monitoring of individuals by multi-professional health teams.

Nevertheless, the strong points of this study, such as the good response rate of the institutionalized subjects and the originality of the study, exceed its limitations because it correlated frequency of dental care for ID persons with oral health indicators and social variables for this type of population. Furthermore, although there are oral health studies that have correlated use of dental services and persons with ID [9-11,21], the authors reinforce the need for literature to show better instruments associated with social support for this type of population, which may justify the non-association of the variables of social support and network with access.

\section{Conclusion}

The DMFT and crowded housing are associated with the frequency of patients with intellectual disability to dental care as well as this outcome measure affect the oral health of individuals with ID. Therefore, identifying limiting factors to dental care of persons with intellectual disability is needed so that this group can receive adequate attention.

Finally, it is suggested that new epidemiological investigations serve as a tool for the future planning of oral health actions in an integrated, effective and resolutive manner, contemplating the demands of this population. However, there is still a long way to go in the scope of policies, of planning and oral health care, until the demands are minimized, not only regarding assistance but, especially, care, from a change in the conceptions of caregivers and, above all, of dentists, focused on integrality and oral health promotion.

\section{Authors' Contributions}

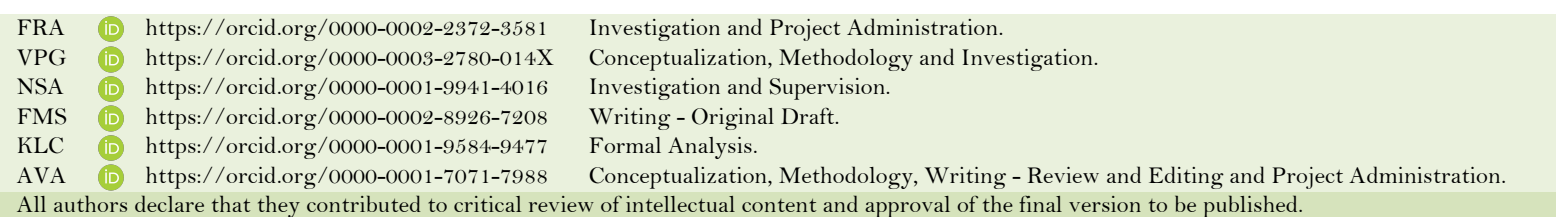

\section{Financial Support}

None.

\section{Conflict of Interest}

The authors declare no conflicts of interest.

\section{Data Availability}

The data used to support the findings of this study can be made available upon request to the corresponding author

\section{Acknowledgments}

The authors of this study are grateful for the all volunteers and institutions of Nova Friburgo that care of special persons - "Associacão de Pais e Amigos dos Excepcionais de Nova Friburgo (APAE), the Municipal School for Special Education - "Escola Estadual Municipalizada de Educacão Especial Neusa Goulart Brizola and the "Universidade Federal Fluminense (UFF), for allowing the research to be conducted

\section{References}

[1] Schalock RL, Borthwick-Duffy SA, Bradley VJ, Buntinx WHE, Coulter DL, Craig EM, et al. Intellectual Disability: Definition, Classification, and Systems of Supports. $11^{\text {th }}$ ed. Washington DC: American Association on Intellectual and Developmental Disabilities; 2010. 254p. 
[2] American Psychiatric Association. Diagnostic and Statistical Manual of Mental Disorders. 5 ${ }^{\text {th }}$ ed. Arlington, VA: American Psychiatric Association; 2013.

[3] World Health Organization. World report on disability. 2011. Available from: https://www.who.int/disabilities/world_report/2011/report.pdf. [Accessed on February 14, 2020].

[4] Brazilian Institute of Geography and Statistics. Demographic Censuses. Available from: https://www.ibge.gov.br/home/estatistica/populacao/censo2010/calendario.shtm. [Accessed on May 2, 2018].

[5] Brazil. Legislative Decree $n^{\circ}$ 186, of July 09, 2008: Decree $n^{\circ}$ 6.949, of August 25, 2009. Convention on the Rights of Persons with Disabilities. Optional Protocol to the Convention on the Rights of Persons with Disabilities. $4^{\text {th }}$ ed. Rev. and current. Brasília: Secretariat of Human Rights, 2010. 100p.

[6] Manhães AL, Costa AJ. Access to and utilization of dental services in the State of Rio de Janeiro, Brazil: an exploratory study based on the 1998 National Household Sample Survey. Cad Saúde Publica 2008; 24(1):207-18. https://doi.org/10.1590/s0102-311 x2008000100021

[7] Vilar RLA, Rocha NSPD, Uchoa AC, Rocha PM. Primary health care access and receptivity to users: an analysis of perceptions by users and health professionals. Cad Saúde Pública 2008; 24(Sup 1):S100-S110. https://doi.org/10.1590/S0102-311X2008001300015

[8] U.S. Department of Health and Human Services. Oral Health in America: A Report of the Surgeon General. Rockville, MD: U.S. Department of Health and Human Services, National Institute of Dental and Craniofacial Research, National Institute of Health, 2000. 332p.

[9] Koneru A, Sigal MJ. Access to dental care for persons with developmental disabilities in Ontario. J Can Dent Assoc 2009; 75(2):121.

[10] Kim YJ, Lim YW, Paik HR, Lee JY, Kim SY. What influences use of dental services by the Korean disabled people? The role of perceived barriers in dental care system. Community Dent Health 2019; 36(2):101-5. https://doi.org/10.1922/CDH_4456Young05

[11] Rocha LL, Saintrain MVL, Vieira-Meyer APGF. Access to dental public services by disabled Persons. BMC Oral Health 2015; 15(35):1-9. https://doi.org/10.1186/s12903-015-0022-x

[12] Von Elm E, Altman DG, Egger M, Pocock SJ, Gotzsche PC, Vandenbroucke JP, et al. Strengthening the Reporting of Observational Studies in Epidemiology (STROBE) statement: guidelines for reporting observational studies. J Clin Epidemiol 2008; 61(4):344-9. https://doi.org/10.1016/j.jclinepi.2007.11.008

[13] Brasil. Lei 8.069, de 13 de Julho de. Estatuto da Criança e do Adolescente. Brasília: Ministério da Justiça, 1990. Available from: https://www.planalto.gov.br/CCIVIL_03/leis/L8069.htm. [Accessed 05 June 2014; 1990]. [In Portuguese]

[14] World Health Organization. Young People's Health — a challenge for society. Report of a WHO Study Group on Young People and Health for All. Technical Report Series 731. Geneva: WHO; 1986.

[15] Alves NS, Gavina VP, Cortellazzi KL, Antunes LA, Silveira FM, Assaf AV. Analysis of clinical, demographic, socioeconomic, and psychosocial determinants of quality of life of persons with intellectual disability: a cross-sectional Study. Spec Care Dentist 2016; 36(6):307-14. https://doi.org/10.1111/scd.12196

[16] Brazil. Ministry of Health. Ministry of Health. Secretariat of Health Care. Department of Basic Attention. National Oral Health Coordination. SB Brazil Project 2010: national oral health research: main results. Report. Brasília: Ministry of Health; 2011. 92p.

[17] Griep RH, Chor D, Faerstein E, Werneck GL, Lopes CS. Construct validity of the Medical Outcomes Study's social support scale adapted to Portuguese in the Pró-Saúde Study. Cad Saúde Pública 2005; 21(3):703-14. https://doi.org/10.1590/S0102-311X2005000300004

[18] World Health Organization. Oral Health Surveys: Basic Methods. $5^{\text {th }}$ ed. Geneve: WHO; 2013.

[19] Baldani MH, Narvai PC, Antunes JLF. Dental caries and socioeconomic conditions in the State of Paraná, Brazil, 1996. Cad Saúde Pública 2002; 18(3):755-63. https://doi.org/10.1590/So102-311X2002000300019

[20] Cortellazzi KL, Pereira SM, Tagliaferro EP, Ambrosano GM, Zanin L, Meneghim MC, et al. Risk indicators of gingivitis in 5-year-old Brazilian children. Oral Health Prev Dent 2008; 6(2):131-7.

[21] Rouleau T, Harrington A, Brenna M, Hammond F, Hirsch M, Nussbaum M, et al. Receipt of dental care and barriers encountered by persons with disabilities. Spec Care Dentist 2011; 31(2):63-7.

https://doi.org/10.1111/j.1754-4505.2011.00178.x

[22] Norderyd J, Faulks D, Molina G, Granlund M, Klingberg G. Which factors most influence referral for restorative dental treatment under sedation and general anaesthesia in children with complex disabilities: caries severity, child functioning, or dental service organisation? Int J Paediatr Dent 2018; 28(1):71-82. https://doi.org/10.1111/ipd.12305

[23] Rocha LL, Saintrain MVL, Vieira APGF-Meyer. Access to dental public services by disabled Persons. BMC Oral Health 2015; 15:35. https://doi.org/10.1186/s12903-015-0022x

[24] Aragão AKR, Souza A, Silva K, Vieira S, Colares V. Acessibilidade da criança e do adolescente com deficiência na atenção básica de saúde bucal do serviço público: um estudo piloto. Pesqui Bras Odontopediatria Clin Integr 2011; 11(2):159-64. https://doi.org/10.4034/PBOCI.2011.112.02 
[25] Cunha ABO, Vieira-da-Silva LM. Health services accessibility in a city of northeast Brazil. Cad Saúde Pública 2010; 26(4):725-37. https://doi.org/10.1590/S0102-311X2010000400015

[26] Glassman P, Caputo A, Dougherty N, Lyons R, Messieha Z, Miler C, et al. Special Care Dentistry Association consensus statement on sedation, anesthesia and alternative techniques for people with special needs. Spec Care Dentist 2009; 29(1):2-8. https://doi.org/10.1111/j.1754-4505.2008.00055.x

[27] Ozkan Y, Özcan M, Kulak Y, Kazazoglu E, Arikan A. General health, dental status and perceived dental treatment needs of an elderly population in Istanbul. Gerodontology 2011; 28(1):28-36. https://doi.org/10.1111/j.1741-2358.2010.00363.x

[28] Moreira RS, Nico LS, Sousa MLR. Factors associated with subjective need for dental treatment in elderly Brazilians. Cad Saúde Pública 2009; 25(12):2661-71. https://doi.org/10.1590/So 102-311X2009001200013

[29] Agili DEAL, Roseman J, Pass MA, Thornton JB, Chavers LS. Access to dental care in alabama for children with special needs. J Am Dent Assoc. 2004; 135(4):490-5. https://doi.org/10.14219/jada.archive.2004.0216

[30] Prabhu NT, Nunn JH, Evans DJ, Girdler NM. Access to dental care - parent's caregivers' views on dental treatment services for people with disabilities. Spec Care Dentist 2010; 30(2):35-45. https://doi.org/10.1111/j.1754-4505.2009.00127.x

[31] Alves FR, Alves NS, Gavina VP, Silveira FM, do Espírito Santo TM, Assaf AV. Accessibility to the oral health of people with Intellectual Disabilities from the caregiver's perspective: a qualitative evaluation. Rev Bras Odontol 2018; 75:e1 107. https://doi.org/10.18363/rbo.v75.2018.e1107

[32] Castro AM, Marchesoti MGN, Oliveira FS, Novaes MSP. Analysis of dental treatment provided under general anesthesia in patients with special needs. Rev Odontol UNESP 2010; 39(3):137-42. 